\title{
Effect of PET Wrapping on Shear Performance of Corroded Reinforced Concrete Columns
}

\author{
Dawei Zhang, Yuxi Zhao, and Weiliang Jin \\ Institute of Structural Engineering, Zhejiang University \\ Tamon Ueda \\ Lab of Engineering for Maintenance System, Hokkaido University
}

\begin{abstract}
In this paper, an experimental study is presented on the influence of PET warping on shear performance, such as diagonal shear cracking load, peak load, and energy dissipation of RC columns with stirrup corrosion before strengthening. The experimental program involved an electrochemical process to accelerate the migration of chlorides from an external electrolyte into the tested columns, a wetting-drying cycle process with a controlled current to speed up the corrosion of the stirrup in the tested columns, the strengthening of corroded columns with PET warping, and a pseudostatic test to determine the shear capacity of the tested beams. The shear performance of PET wrapped RC columns with different corrosion levels in stirrups, including the diagonal cracking strength, the peak strength, the ductility ratio, and the energy dissipation ability, was examined and compared.
\end{abstract}

Keywords: corrosion, strengthening, shear, energy dissipation, column

\section{INTRODUCTION}

Large hoop spacing and lack of stirrup anchorage at the plastic hinge locations of columns may lead to spalling of cover concrete and buckling of column longitudinal bars in concrete columns under the effect of earthquake-induced reversed moments. Meanwhile, reinforcement corrosion has been observed to a great extent, especially in the marine environment. Past experiences have shown that reinforcement corrosion reduces the beam and column capacity due to steel area losses, bond deterioration, reduction in the effective concrete area, etc. (Li \& Li, 2014; Ma, Che, \& Gong, 2012; Pantazopoulou, Bonacci, Sheikh, Thomas, \& Hearn, 2001). Despite a large body of literature on the influence of reinforcing steel corrosion on the flexural capacity of RC columns, there are few works that have dealt with the reduction in shear capacity of $R C$ columns due to the corrosion of stirrups (Xia, Jin, \& Li, 2011). Actually, stirrups would be first attacked by chlorides in a chloride environment since they are nearer to the concrete surface than the longitudinal steel bars.

Extensive investigations on the seismic retrofitting of reinforcedconcrete $(\mathrm{RC})$ columnshave beenundertaken in recent years. There has been an enormous interest in the research and application of fiber reinforced polymers (FRPs) in RC column seismic retrofitting since the 1980s. The basic concepts and relatively recent survey in the use of FRPs for strengthening of concrete structures are covered in a review article by Triantafillou (2001). Many researchers have proven the effectiveness of applications of conventional FRP materials, such as aramid, carbon, and glass, in shear and ductility enhancement (Bakis et al., 2002; Benzaid, Chikh, \& Mesbah, 2008; Teng, Chen, Smith, \& Lam, 2003; Wu et al., 2006). However, due to low fracturing strain capacity of conventional FRPs [around 1.5\% for carbon FRP (CFRP), 2\% for glass FRP (GFRP), and $3 \%$ for aramid FRP (AFRP)], the fiber materials tend to fail sooner due to fiber breakage, which causes a loss of confinement and hence the load-carrying capacity as well as the ductility potential. New fiber materials, such as polyacetal fiber (PAF), polyethylene naphthalate (PEN), and polyethylene terephthalate (PET), have properties of large fracturing strain and low stiffness in comparison to aramid, carbon, and glass fibers (Jirawattanasomkul, Dai, Zhang, Senda, \& Ueda, 2013). Previous studies (Anggawidjaja, Ueda, Dai, \& Nakai, 2006; Dai, Bai, \& Teng, 2011; Dai, Lam, \& Ueda, 2012) proved that concrete or RC members wrapped by PET and PEN fiber sheets with large fracturing strain could efficiently enhance the ductility of concrete or RC members, regardless of their low stiffness. However, the effect of steel corrosion on the efficiency of FRP wrapping to enhance the member behavior and the corresponding remains unclear.

In this paper, an experimental study is presented on the influence of PET warping on shear strength, ductility, and energy absorptivity of RC columns with stirrup corrosion before strengthening. The experimental program involved an electrochemical process to accelerate the migration of chlorides from an external 
electrolyte into the tested columns, a wetting-drying cycle process with a controlled current to speed up the corrosion of the stirrup in the tested columns, the strengthening of corroded columns with PET warping, and a pseudostatic test to determine the shear capacity of the tested beams. The shear performance of PET wrapped RC columns with different corrosion levels in stirrups was examined.

\section{EXPERIMENTAL PROGRAM}

\subsection{Details of test setup}

A total of $11 \mathrm{RC}$ rectangular columns with footings were constructed, which consisted of four unstrengthened control specimens with different levels of stirrup corrosion (designed to be $0 \%, 10 \%, 15 \%$, and $25 \%$ ) and seven strengthened specimens with different layers of PET fiber warping (one or two layers), as indicated in Table 1. The acronym designation adopted for the specimens was as follows: "C" represents corrosion pre-damage, the number following " $C$ " stands for degree of corrosion of stirrups before strengthening, "L" means PET warping, and the last number corresponds to the number of warping layers. For example, specimen "C-10-L-2" is the RC column with expected degree of corrosion of stirrups of $10 \%$, which was warped by two layers of PET fiber.

Table 1. Parameters of test specimens.

\begin{tabular}{lccc}
\hline Specimens & Strengthening & $\begin{array}{c}\text { Targeted } \\
\text { corrosion ratio (\%) }\end{array}$ & $\begin{array}{c}\text { PET } \\
\text { layers }\end{array}$ \\
\hline C-0-L-0 & No & 0 & 0 \\
C-0-L-1 & Yes & 0 & 1 \\
\hline C-10-L-0 & No & 10 & 0 \\
C-10-L-1 & Yes & 10 & 1 \\
C-10-L-2 & Yes & 10 & 2 \\
\hline C-15-L-0 & No & 15 & 0 \\
C-15-L-1 & Yes & 15 & 1 \\
C-15-L-2 & Yes & 15 & 2 \\
\hline C-25-L-0 & No & 25 & 0 \\
C-25-L-1 & Yes & 25 & 1 \\
C-25-L-2 & Yes & 25 & 2 \\
\hline
\end{tabular}

The column had a cross section of $250 \mathrm{~mm} \times 250 \mathrm{~mm}$ and a total height of $740 \mathrm{~mm}$. The corners of columns to be strengthened were rounded with a rounding radius of $20 \mathrm{~mm}$. The footings had a size of $700 \mathrm{~mm} \times 450 \mathrm{~mm} \times 360 \mathrm{~mm}$ (length $\times$ width $\times$ height). Each specimen used eight $25-\mathrm{mm}$ deformed bars for longitudinal reinforcement and $10-\mathrm{mm}$ plain bars for stirrups spaced at $100 \mathrm{~mm}$. Span-to-effective depth ratio was equal to 2.89 . The longitudinal reinforcements in the columns were extended into the footing with a sufficient anchorage length. Details of the reinforcement arrangement are shown in Figure 1.
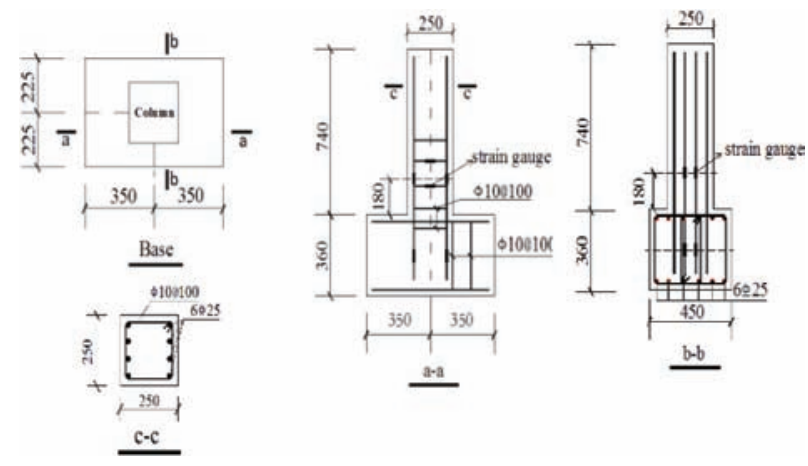

Figure 1. Geometry and reinforcement information of specimens (unit: $\mathrm{mm}$ ).

\subsection{Material properties}

Same batch of ready-mixed concrete was used to cast the specimens. The 28-day cubic $(150 \mathrm{~mm} \times 150 \mathrm{~mm} \times 150 \mathrm{~mm})$ compressive strength of concrete was $32.7 \mathrm{MPa}$. The epoxy resin used for PET warping had a tensile strength of $41.0 \mathrm{MPa}$, elastic modulus of $2.6 \mathrm{GPa}$, and an elongation at break of $1.6 \%$, as provided by the manufacturer. Tables 2 and 3 show the properties of the reinforcement and PET fiber sheet used in this experiment obtained through uni-axial tensile coupon test.

Table 2. Mechanical properties of steel bars.

\begin{tabular}{lccccc}
\hline Bars & $\begin{array}{c}\text { Diameter } \\
(\mathbf{m m})\end{array}$ & $\begin{array}{c}\text { Yield } \\
\text { stress } \\
(\mathbf{M P a})\end{array}$ & $\begin{array}{c}\text { Ultimate } \\
\text { stress } \\
\mathbf{( M P a})\end{array}$ & $\begin{array}{c}\text { Exten- } \\
\text { sion } \\
\text { ratio (\%) }\end{array}$ & $\begin{array}{c}\text { Tensile } \\
\text { modulus } \\
(\mathbf{M P a})\end{array}$ \\
\hline $\begin{array}{l}\text { Longitu- } \\
\text { dinal bar }\end{array}$ & 25 & 476 & 580 & 38.2 & $2.12 \times 10^{5}$ \\
\begin{tabular}{l} 
Stirrup \\
\hline
\end{tabular} & 10 & 342 & 499 & 36.2 & $2.03 \times 10^{5}$ \\
\hline
\end{tabular}

Table 3. Mechanical properties of PET sheet.

\begin{tabular}{lccccc}
\hline Name & $\begin{array}{c}\text { Tensile } \\
\text { strength } \\
\mathbf{f t u}(\mathbf{M P a})\end{array}$ & $\begin{array}{c}\text { Tensile } \\
\text { modulus } \\
\text { Ef (GPa) }\end{array}$ & $\begin{array}{c}\text { Ultimate } \\
\text { strain } \\
\mathbf{( \% )}\end{array}$ & $\begin{array}{c}\text { Area } \\
\text { density } \\
\mathbf{r}\left(\mathbf{g} / \mathbf{m}^{2}\right)\end{array}$ & $\begin{array}{c}\text { Thickness } \\
(\mathbf{m m})\end{array}$ \\
\hline PET & 719 & 9.35 & $\geq 7 \%$ & 1161 & 0.841 \\
\hline
\end{tabular}

\subsection{Accelerated corrosion procedure}

In order to reduce the experimental time to match the corrosion process and behavior happened in real RC members, an accelerated corrosion procedure suggested by Xia et al. (2011) was applied. In the electro-migration phase, chloride ions were electro-migrated into the concrete cover using an 
electrochemical method. A constant voltage of $30 \mathrm{~V}$ was then applied between the outside stainless steel nets and the embedded stainless steel sheets using a DC power source. A wetting-drying cycle process was used immediately after the electromigration process. Each cycle of the wettingdrying process involved 3 days of drying followed by 4 days of wetting in $5 \% \mathrm{NaCl}$ solution. A current density of $0.20 \mathrm{~mA} / \mathrm{cm}^{2}$ was applied through the stirrups (acting as the anode) and the stainless steel nets (acting as the cathode). The specimens were corroded within $300-\mathrm{mm}$ portion of the plastic hinge zone. The longitudinal reinforcement was coated with epoxy paint at its intersection with stirrup to inhibit corrosion. The estimated time for corrosion was calculated based on Faraday's law. The wetting-drying cycles lasted for 7,10 , and 16 weeks for the expected degree of corrosion of $10 \%, 15 \%$, and $25 \%$, respectively.

\subsection{Instrumentation and testing procedure}

As shown in Figure 2, the specimens were subjected to a combination of cyclic horizontal load and constant axial load. The compressive vertical load represents the service and dead load of superstructures and equals to $180 \mathrm{kN}$, which is about $30 \%$ of the expected axial loading capacity of un-corroded control column. A 500-kN closedloop MTS actuator was used to apply the horizontal cyclic load. The cyclic tests were first conducted under load control for load cycles at 20-kN intervals until the load reached $140 \mathrm{kN}$, which was equal to the predicted yielding load of control beams. The horizontal load was adopted to control the loading procedure. In the second phase, the specimens were loaded cyclically under displacement control at $5-\mathrm{mm}$ intervals until the failure of the specimens. The horizontal displacement of the actuator was adopted to control the loading procedure. Load and displacement can be controlled and recorded during the tests by a computer connected to the hydraulic actuator.

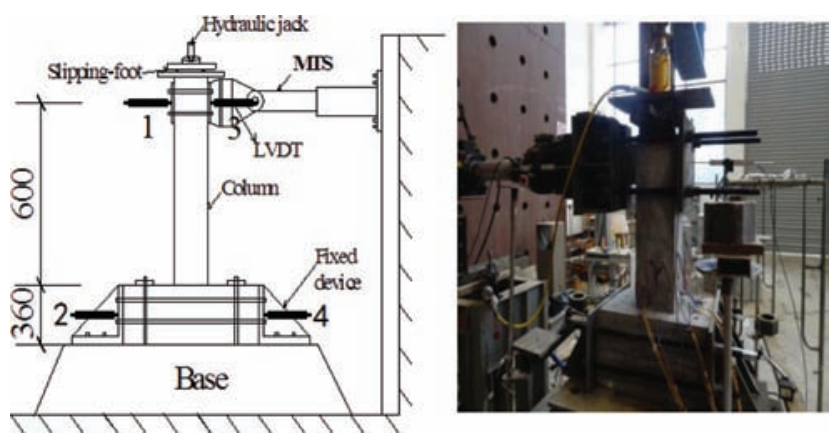

Figure 2. Illustration of loading apparatus.
Two transducers (LVDT) were mounted on the rigid frames to measure lateral displacement of columns. Two LVDTs were mounted at the footing to measure horizontal slip and rotation of the footing, as indicated in Figure 3.

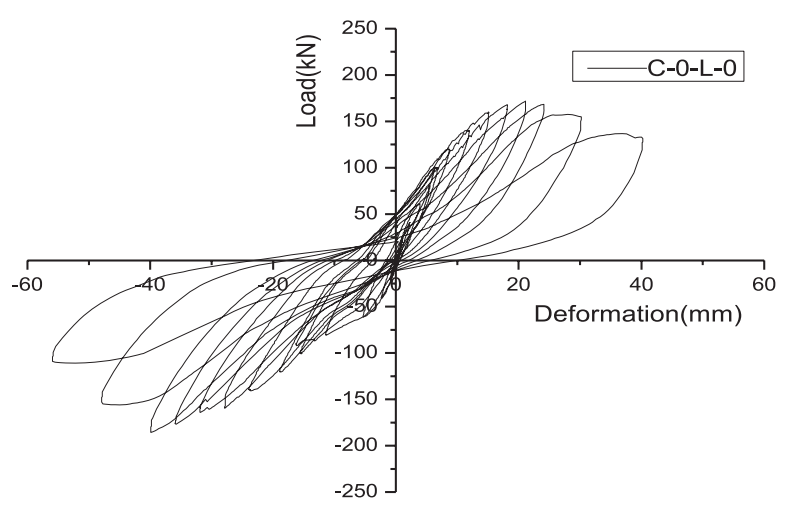

Figure 3. Typical hysteric response of specimen.

\section{RESULTS AND DISCUSSIONS}

\subsection{Corrosion damage}

After the accelerated corrosion process, cracks due to corrosion were observed for series. The corrosion cracks were primarily horizontal at the locations of the stirrup with the secondary cracks that were oriented along the longitudinal reinforcement. The corrosion cracks were associated with rust stains while no delamination of the concrete cover appeared for all the corroded specimens.

After loading the test specimens to failure, the stirrups were extracted. All damage states exhibited significant areas of pitting. The damage for specimens of $10 \%$ and $15 \%$ expected corrosion ratio was localized section loss with some uniform section loss. The damage for specimens of $25 \%$ expected corrosion ratio showed significant localized and uniform section loss. The section loss was mainly on the outward facing side of bar and generally was greater at or near the bends in the stirrups. Four coupons with a length of $100 \mathrm{~mm}$ within the targeted $300-\mathrm{mm}$ long corrosion area per stirrup per column were cleaned and used for the purpose of calculating mass loss following the ASTM G1-03 (2011). The weight of the stirrup without corrosion was determined by weighing the $100-\mathrm{mm}$ long stirrup in the un-corroded zone of the same column such that the weight of the extracted coupons after corrosion could be compared to the original weight and the mass loss due to corrosion could be estimated. The average measured mass loss (degree of corrosion) and its standard deviation in the stirrups of the corroded columns are listed in Table 4. It can be concluded that the expected mass losses were achieved in the laboratory. 
Table 4. Summary of test results.

\begin{tabular}{lcccc}
\hline Specimens & $\begin{array}{c}\text { Average } \\
\text { corrosion } \\
\text { degree } \\
\eta_{\text {ave }}(\%)\end{array}$ & $\begin{array}{c}\text { Diagonal } \\
\text { cracking } \\
\text { load } \mathbf{P}_{\mathbf{c}} \\
\mathbf{( k N )}\end{array}$ & $\begin{array}{c}\text { Peak } \\
\text { load } \\
\mathbf{P}_{\text {max }} \\
(\mathbf{k N})\end{array}$ & $\begin{array}{c}\text { Accumulated } \\
\text { energy } \\
\text { dissipation } \\
\mathbf{E}_{\text {sum }}(\mathbf{k N} \times \mathbf{m})\end{array}$ \\
\hline C-0-L-0 & 0 & 50.2 & 185.0 & 63.6 \\
C-0-L-1 & 0 & 80.2 & 245.0 & 135.3 \\
\hline C-10-L-0 & 10.66 & 53.4 & 160.3 & 41.9 \\
C-10-L-1 & 9.91 & 87.2 & 198.1 & 131.1 \\
C-10-L-2 & 11.2 & 90.3 & 209.7 & 148.6 \\
\hline C-15-L-0 & 15.63 & 47.6 & 169.8 & 43.9 \\
C-15-L-1 & 16.26 & 91.4 & 181.5 & 115.9 \\
C-15-L-2 & 16.82 & 92.7 & 211.9 & 122.4 \\
\hline C-25-L-0 & 21.66 & 55.6 & 140.0 & 44.1 \\
C-25-L-1 & 22.78 & 86.1 & 191.7 & 162.8 \\
C-25-L-2 & 19.86 & 86.7 & 195.1 & 133.6 \\
\hline
\end{tabular}

\subsection{Failure mode}

All un-strengthened specimens showed brittle shearcompression failure with extensive $\mathrm{X}$-shaped diagonal concrete shear cracks together with the spalling or crushing of cover concrete. For all PET strengthened specimens, the PET fiber sheet showed no breakage till the end of the test, although some parts were found debonding from the concrete surface, while crushing of concrete was also observed after removing the PET sheet. For all the specimens, no bucking of longitudinal reinforcements was observed.

\subsection{Hysteretic response and energy dissipation ratio}

Due to space limitation, the sample hysteretic responses of several tested specimens are shown in Figure 3. The skeleton curve of all the specimens are presented in Figure 4.The lateral load at the first diagonal crack $\left(P_{c}\right)$ and the maximum load $\left(P_{\text {max }}\right)$ are summarized in Table 4.

Energy dissipation ratio has been used to evaluate the energy dissipation ability of structures under cyclic loading. The energy dissipation ratio at each load cycle of each specimen was calculated using Eq. (1). The accumulated energy dissipation $\left(E_{\text {sum }}\right)$ is calculated using Eq. (2).

$$
\begin{aligned}
& E_{r}=\frac{S_{(A B C+C D A)}}{S_{(O B E+O D F)}} \\
& E_{\text {sum }}=\sum_{i=1}^{n}\left(E_{i}\right)
\end{aligned}
$$

where $E_{i}$ is the energy dissipation of ith load cycle, $E_{\text {sum }}$ is the accumulated energy dissipation, and $n$ is the number of loading cycles. The accumulated energy dissipations of test specimens are presented in Table 4.

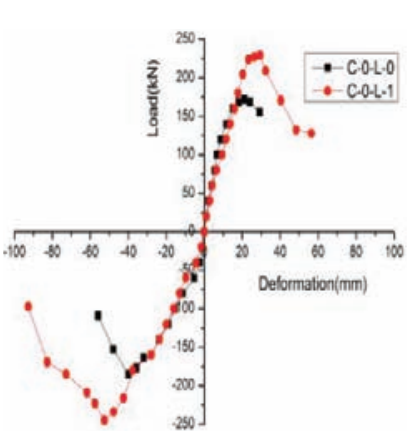

(a) C-0 series

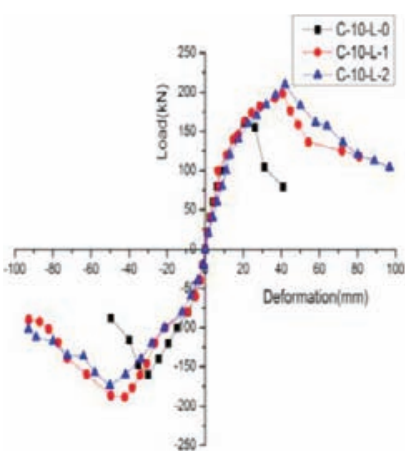

(b) C-10 series

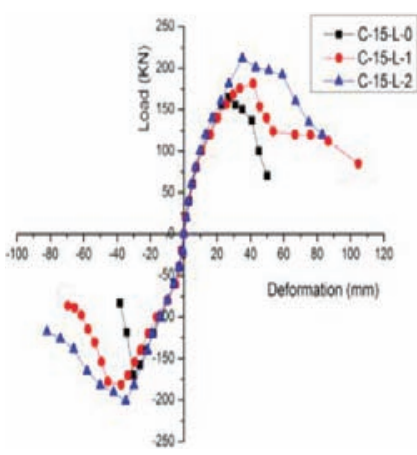

(c) $\mathrm{C}-15$ series

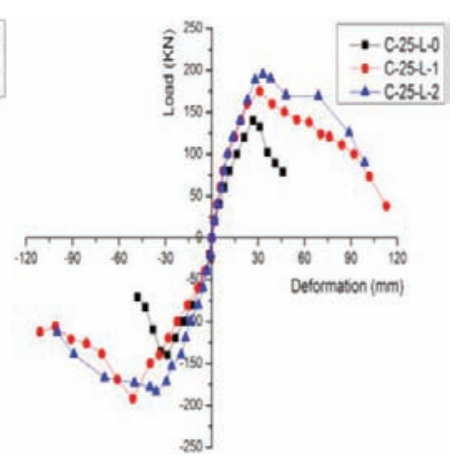

(d) C-25 series

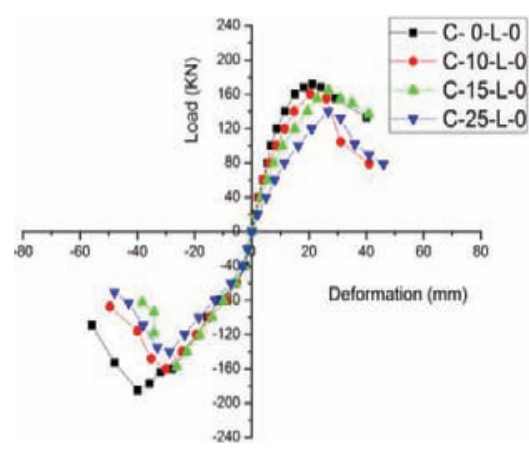

(e) L-0 series

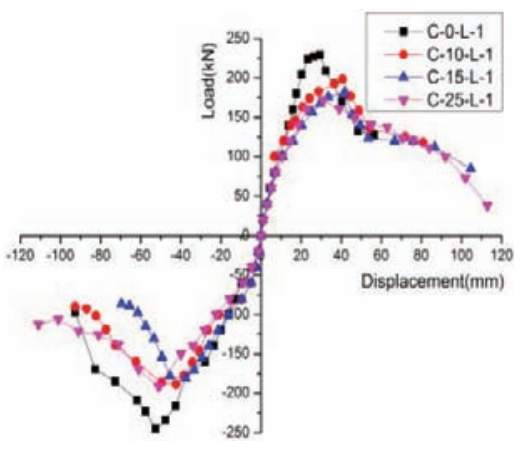

(f) L-1 series

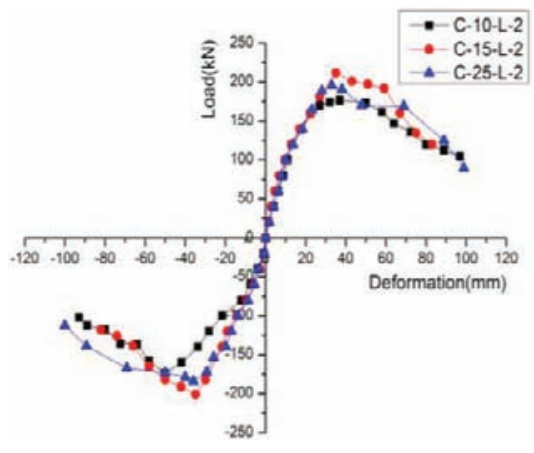

(g) L-2 series

Figure 4. Skeleton curves of the test specimens. 


\subsection{Effect of stirrup corrosion}

Figure 4 shows the lateral load-displacement skeleton curves of all the specimens and the corresponding diagonal cracking load and peak load are listed in Table 4. For un-strengthened columns, diagonal cracking of concrete web occurred at lower loads. The un-corroded specimens exhibited higher stiffness after diagonal cracking than corroded specimens. The stiffness degradation in the corroded specimens can be attributed to the corrosion cracking and loss of bond between the corroded stirrups and concrete.

As shown in Figures 5-7, for both un-strengthened and strengthened columns, the diagonal cracking load varied and the peak load and accumulated energy dissipation decreased with the increase of degree of stirrup corrosion. The corrosion of the stirrups caused deterioration of the bond between the concrete and the stirrups, and cover concrete cracking, which reduced the effective concrete area for load bearing and energy assumption.

\subsection{Effect of PET warping}

The un-strengthened specimens showed brittle behavior after the peak load, while the specimens with PET warping showed sudden drop of load carrying capacity after the peak load to a certain level and

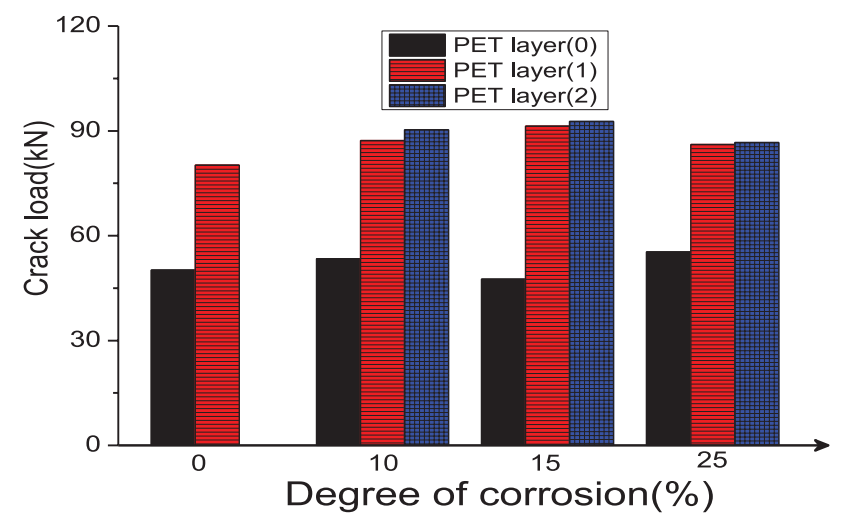

(a) Diagonal crack load

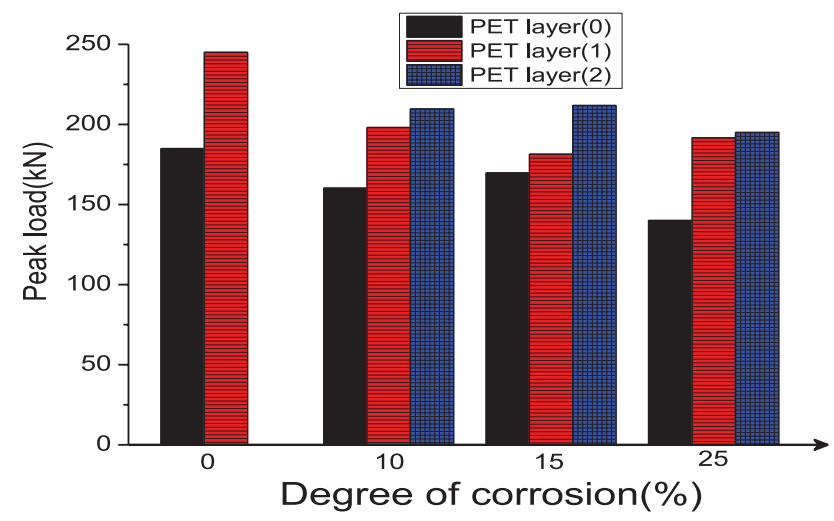

(b) Peak load

Figure 5. Effect of stirrup corrosion

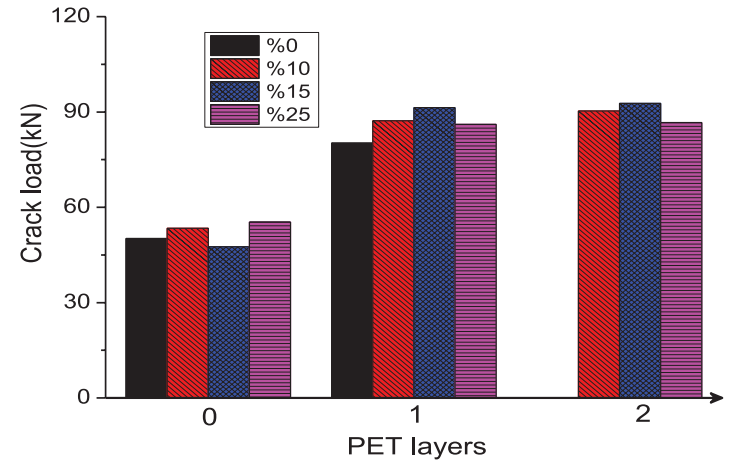

(a) Diagonal crack load

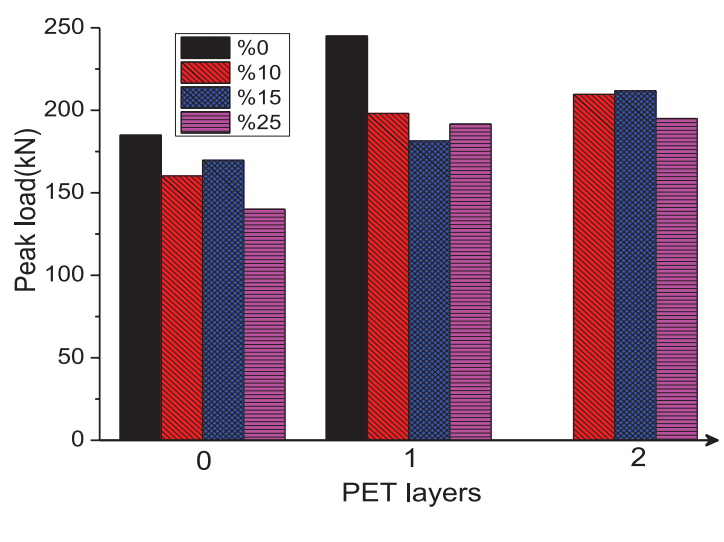

(b) Peak load

Figure 6. Effect of PET area.

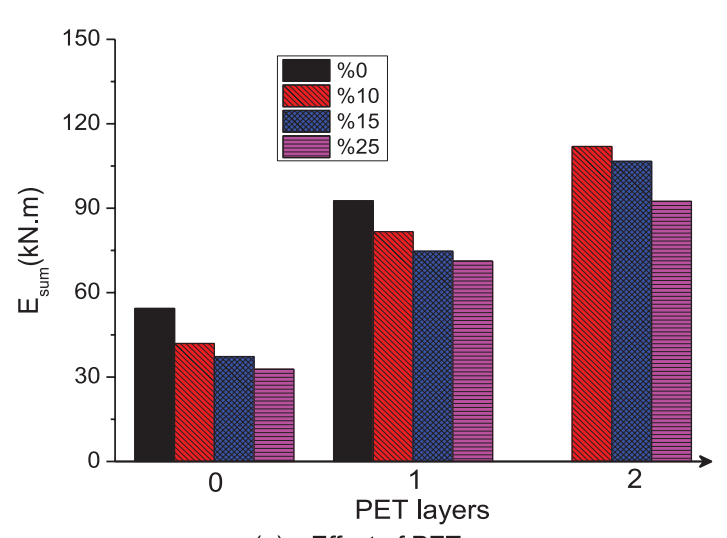

(a) Effect of PET area

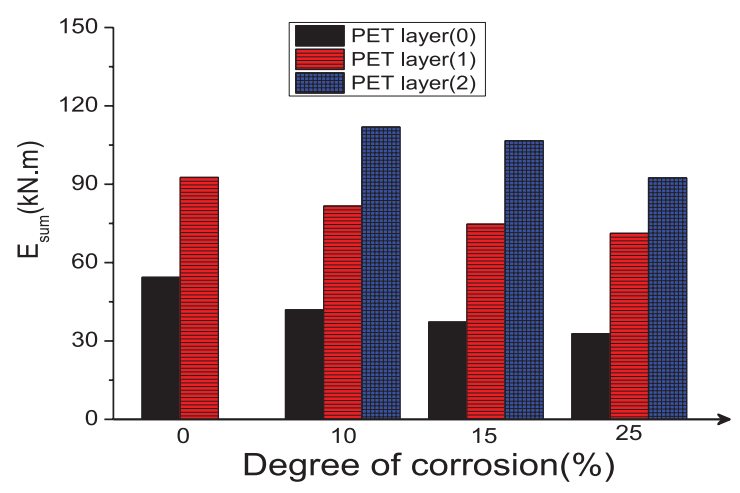

(b) Effect of PET area

Figure 7. Accumulate energy dissipation. 
then exhibited a ductile response. The peak load was reached after the yielding of stirrups, which caused crushing of cover concrete. As shown in Figures 5-7 and Table 4, the peak load and the accumulated energy dissipation after PET warping comparing to the un-strengthened columns with similar degree of stirrup corrosion was enhanced, while the diagonal cracking load differed little. The enhancement was more obvious with the increase of number of PET layers. The effect of stirrup corrosion on the peak load was reduced after the PET warping. Although the specimens were designed with insufficient shear capacity, the PET confinement could provide additional shear capacity and confinement to the concrete, which delayed the crushing of concrete and could still carry the shear force after that.

\section{CONCLUSION}

This paper presented the experimental study on the influence of PET warping on shear performance of RC columns with stirrup corrosion before strengthening. The following conclusions can be drawn:

1. For un-strengthened columns, the diagonal cracking load varied, while the peak load, ductility ratio, and energy dissipation ratio decreased with the increase of degree of stirrup corrosion.

2. The diagonal cracking load, peak load, and accumulated energy dissipation after PET warping comparing to the un-strengthened columns with similar degree of stirrup corrosion was enhanced. The enhancement was more with the increase of number of PET layers.

\section{ACKNOWLEDGMENTS}

Final support from the Fundamental for the Central Universities (2015FZA4018) and Research Fund of Ministry of transport construction technology (2014318494020) are greatly appreciated.

\section{REFERENCES}

ACI 318 Committee. (2011). Building code requirements for structural concrete (ACl 318-11) and commentary. American Concrete Institute, p. 503.

Anggawidjaja, D., Ueda, T., Dai, J., \& Nakai, H. (2006). Deformation capacity of RC piers wrapped by new fiber-reinforced polymer with large fracture strain. Cement and Concrete Composites, 28(10), 914-927.

ASTM G1-03. (2011). Standard practice for preparing, cleaning, and evaluating corrosion test specimens. West Conshohocken, PA: ASTM International.
Bakis, C., Bank, L. C., Brown, V., Cosenza, E., Davalos, J. F., Lesko, J. J., ... Triantafillou, T. C. (2002). Fiber-reinforced polymer composites for construction-state-of-the-art review. Journal of Composites for Construction, 6(2), 73-87.

Benzaid, R., Chikh, N. E., \& Mesbah, H. (2008). Behaviour of square concrete column confined with GFRP composite warp. Journal of Civil Engineering and Management, 14(2), 115-120.

CEB-FIP Model Code 2010. (2010). Comité EuroInternational du Béton Secretariat Permanent. Lausanne, Switzerland.

Dai, J. G., Bai, Y. L., \& Teng, J. G. (2011). Behavior and modeling of concrete confined with FRP composites of large deformability. Journal of Composites for Construction.

Dai, J. G., Lam, L., \& Ueda, T. (2012). Seismic retrofit of square $\mathrm{RC}$ columns with polyethylene terephthalate (PET) fibre reinforced polymer composites. Construction and Building Materials, 27(1), 206-217.

Gao, Y., Wang, Q., Zhao, B., \& Shi, Y. (2014). A rupture blank zone in middle south part of Longmenshan faults: Effect after Lushan M s7. 0 earthquake of 20 April 2013 in Sichuan, China. Science China Earth Sciences, 57(9), 2036-2044.

Japan Society of Civil Engineers. (2012). Standard specification for concrete structures: Design. Author.

Jirawattanasomkul, T., Dai, J. G., Zhang, D., Senda, M., \& Ueda, T. (2013). Experimental study on shear behavior of reinforced-concrete members fully wrapped with large rupture-strain FRP composites. Journal of Composites for Construction, 18(3), A4013009.

Li, J. H., \& Li, Y. (2014). Experimental and theoretical study on the seismic performance of corroded $\mathrm{RC}$ circular columns strengthened with hybrid fiber reinforced polymers. Polymers \& Polymer Composites, 22(8), 653-659.

Ma, Y., Che, Y., \& Gong, J. X. (2012). Behavior of corrosion damaged circular reinforced concrete columns under cyclic loading. Construction and Building Materials, 29, 548-556.

Pantazopoulou, S. J., Bonacci, J. F., Sheikh, S., Thomas, M. D. A., \& Hearn, N. (2001). Repair of corrosion-damaged columns with FRP wraps. Journal of Composites for Construction, 5(1), 3-11.

Tapan, M., \& Aboutaha, R. S. (2011). Effect of steel corrosion and loss of concrete cover on strength of deteriorated RC columns. Construction and Building Materials, 25(5), 2596-2603. 
Teng, J. G., Chen, J. F., Smith, S. T., \& Lam, L. (2003). Behaviour and strength of FRPstrengthened RC structures: A state-of-the-art review. Proceedings of the ICE-Structures and Buildings, 156(1), 51-62.

Triantafillou, T. C. (2001). Seismic retrofitting of structures with fiber-reinforced polymers. Progress in Structural Engineering and Materials, 3(1), 57-65.
Wang, Y. (2008). Lessons learnt from building damages in the Wenchuan earthquake - Seismic concept design of buildings [J]. Journal of Building Structures, 4, 004.

Xia, J., Jin, W. L., \& Li, L. Y. (2011). Shear performance of reinforced concrete beams with corroded stirrups in chloride environment. Corrosion Science, 53(5), 1794-1805. 